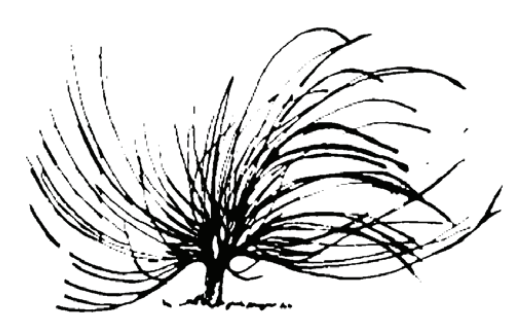

\title{
El Juego como Estrategia Metodológica en el Desarrollo de Habilidades Sociales para el Liderazgo en la Niñez
}

\author{
Ana Azofeifa Lizano ${ }^{1}$ \\ Universidad Nacional \\ Heredia, Costa Rica \\ anaazofeifa@gmail.com \\ Marjorie Cordero Pereira
Colegio Yurusti
Heredia, Costa Rica
cordero.marjorie@gmail.com
}

\section{Resumen}

El presente artículo se deriva de una investigación, la cual tuvo como propósito identificar los conocimientos que poseen los docentes de primer ciclo de un centro educativo privado en Heredia, sobre el juego como estrategia metodológica en el desarrollo de habilidades para el liderazgo en niños y niñas. Con el fin de registrar el

(c) (i) (s) $(9$

Recibido: 18 de agosto de 2015-Aprobado: 4 de diciembre de 2015

1 Máster en Gestión Educativa con énfasis en Liderazgo, Licenciatura en Ciencias de la Salud y el Deporte y Bachiller en Educación Física Deporte y Recreación. Tiene una experiencia de 12 años en educación en las áreas de preescolar, primaria, secundaria y universitaria. Además, ha participado como organizadora de congresos y campamentos juveniles a nivel nacional e internacional en áreas de crecimiento espiritual y liderazgo. Actualmente, docente de la División de Educología del Centro para la Investigación y Docencia en Educación (CIDE) de la Universidad Nacional.

2 Máster en Gestión Educativa con énfasis en Liderazgo, Máster en Psicología Organizacional, Licenciada en Diseño de Interiores. Técnica en Administración de Empresas y Especialista en Motivación y Liderazgo. Profesional con 12 años de experiencia laboral en instituciones educativas enfocadas en roles administrativos (recursos humanos y gerencia de proyectos), se ha desempeñado, a su vez, como consultora en desarrollo de talentos, liderazgo y motivación. Actualmente, se desempeña como Gestora de Talento Humano en el Colegio Yurusti. 
proceso de sistematización se diseñó un cuestionario con doce preguntas, además se revisó documentación de planeamientos trimestrales. En la investigación participaron ocho docentes de primer ciclo. Los principales resultados muestran que solamente cuatro docentes utilizan el juego en sus clases y son dirigidos a reforzar el área cognitiva. Las conclusiones indicaron que aunque las docentes manifestaron hacer uso del juego en sus lecciones, no hay evidencia en sus planeamientos de estrategias metodológicas que los utilicen, ni claridad en el dominio de términos sobre liderazgo, habilidades de liderazgo o habilidades sociales.

Palabras clave: juego, liderazgo, docente, metodología, habilidades

\begin{abstract}
This article is derived from a research which aimed at identifying the knowledge possessed by teachers of first cycle of a private school in Heredia about game as a methodological strategy for developing leadership skills in children. To record the systematization process, we designed a questionnaire of twelve questions. Also, the teachers' trimestral plans were reviewed. Eight teachers participated in this research. The main results show that only four teachers use games in their classes, and that these are aimed at strengthening cognitive aspects. The findings indicated that although teachers reported the use of the game in their lessons, there is no evidence of methodological strategies in their planning or clarity in the domain of terms like leadership, leadership skills, and social skills.
\end{abstract}

Keywords: Game, teacher, leadership, methodology, skills 


\section{Introducción}

El juego constituye un elemento importante en la vida de los seres humanos, es pieza fundamental en el desarrollo integral de los niños y niñas, estrechamente ligado a las cuatro dimensiones básicas del desarrollo infantil: psicomotor, intelectual, social y afectivo-emocional. Tal y como lo señalan García y Alarcón (2011) "como una actividad vital e indispensable para el desarrollo humano, ya que contribuye en lo psicomotriz, afectivo-social e intelectual".

Desde el punto de vista de la dimensión social, Garaigordobil (2009) menciona que cuando los niños y las niñas juegan, entran en contacto con sus iguales, aprenden a descubrirse a sí mismos y a los demás.

Vinculado a esta dimensión social del juego, García (2010, párr. 9) hace mención de algunos de los objetivos de la institución educativa, que pueden cumplirse por medio del juego, como son enseñar a los estudiantes a tomar decisiones ante problemas que pueden surgir en su vida; garantizar la posibilidad de la adquisición de una experiencia práctica del trabajo colectivo y el análisis de las actividades organizativas de los estudiantes. Todo lo anterior vinculado a la vida social cotidiana.

Cuando los niños y niñas juegan se extienden sus fronteras de la comunicación, aprenden a respetar a los demás y sus puntos de vista, llegan a acuerdos y a defender sus ideas, de ahí la importancia de propiciar espacios lúdicos en la escuela y el hogar.

En este sentido, Romero, Escorihuela y Ramos (2009) mencionan que desde la perspectiva social de la escuela, esta tiene encomendada una serie de tareas orientadas a contribuir al desarrollo personal, físico, intelectual, afectivo y relacional del niño y la niña, intentando integrar a la persona en la comunidad como un miembro activo y participativo.

En un estudio realizado por Restrepo y Londoño (2008), se identificó que durante la ejecución de las diferentes sesiones en una clase lúdica, fue evidente la importancia de las actividades grupales, donde los estudiantes manifestaron que estas son indispensables para reconocer al otro y reconocerse a sí mismo en un colectivo. Para García (2010), el juego crea en los estudiantes habilidades del trabajo interrelacionado de colaboración en el cumplimiento conjunto de tareas, aspecto relevante en el liderazgo.

La estimulación lúdico recreativa en la niñez es un componente indispensable en la formación de seres integrales; por eso esta propuesta 
de investigación cobra valor en la medida en que cada día, más padres, madres y cuerpo docente sean conscientes de que la interacción entre los niños y las niñas, en ambientes conocidos por ellos y ellas es de gran ayuda para su desarrollo social y emocional. Por lo tanto, se planteó como objetivo general identificar los conocimientos que poseen los docentes de primer ciclo de un centro educativo privado de Heredia sobre el juego como estrategia metodológica para el desarrollo de habilidades sociales para el liderazgo en la niñez.

\section{Marco teórico}

\section{La metodología y el papel del docente}

La palabra método, viene del griego de las palabras metá que significa "hacia lo largo", y odos, "camino", por lo que se puede considerar como caminos didácticos para alcanzar un fin, algo planificado que, en este caso, es el aprendizaje del estudiante. El método es el modo de desarrollar la práctica diaria. Para De la Herrán (2008), la metodología manifiesta las intenciones educativas docentes tales como "concepción de educación, de enseñanza, de su didáctica específica, la idea que tiene del alumno, sus conocimientos aplicados a los elementos curriculares básicos (...) competencias, contenidos, criterios de evaluación, sus valores educativos" (p. 138).

De este modo, según Carbonell (citado por Sales, 2005) la idoneidad metodológica está en función de los objetivos educativos que quieran lograrse y del modelo pedagógico de referencia.

Romero et al. (2009) aseguran que el docente tiene la responsabilidad de enriquecer su práctica pedagógica con estrategias innovadoras y creativas. La formación permanente de los docentes es un proceso que demanda el dominio de los contenidos y procedimientos para enseñar, por ell hay que valerse de estrategias que permitan alcanzar el interés del niño y la niña en los contenidos a desarrollar. Cabe preguntarse, ¿qué son las estrategias? Según Huerta (citado) por Romero et al., (2009) las estrategias son aquellas que permiten conectar una etapa con la otra en un proceso; es la unión entre el concepto y el objeto. Visto así, para estos autores las estrategias deben dirigirse a los alumnos tomando en cuenta los contenidos que sean necesarios para su interés y, a su vez, contar con una motivación entre el profesor y los estudiantes. 
Dentro del proceso enseñanza aprendizaje, los y las docentes deben disponer de espacios que permitan a los niños y niñas descubrir su entorno de manera participativa y dinámica, como se permite en el juego, donde la niña y el niño pueden afrontar las diferentes situaciones que se le presenten en sus relaciones y vivencias personales y no sólo el reforzamiento cognitivo. Desde este punto de vista, el sistema educativo debe ser consciente del niño y niña como ser integral y mirar la herramienta natural de aprendizaje que implica el juego.

\section{EI Juego y las habilidades sociales}

Para Torres (2002),el juego debe considerarse como una actividad importante puesto que aporta una forma diferente de adquirir el aprendizaje, aporta descanso y recreación al estudiante.

El ambiente lúdico permite a los niños y niñas interiorizar nuevos conceptos, donde cobran significatividad, es en esos espacios donde se manifiestan emociones e ideas propias, cuando el niño y la niña juegan se generan preguntas y se buscan respuestas, al respecto Garaigordobil (2009) asegura que:

Juegos como los cooperativos promueven la comunicación, aumentan los mensajes positivos entre los miembros del grupo y disminuyen los mensajes negativos, incrementan las conductas pro sociales y las conductas asertivas en la interacción con iguales, disminuyen conductas sociales negativas, y potencian la participación en actividades de clase y la cohesión grupal, todo lo anterior mejorando el clima social de aula y el concepto de uno mismo y de los demás. (párr. 6)

El juego da la oportunidad para que se den una serie de interacciones entre sus participantes que en otros ambientes no son posibles, entre ellas el desarrollo de habilidades sociales, a lo cual Rodríguez (2013) se refiere como, "un conjunto de capacidades que desarrollan un repertorio de acciones y conductas que hacen que las personas se desenvuelvan eficazmente en lo social" (Educar para las relaciones sociales. párr.1) además, añade que estas habilidades, fruto del aprendizaje y de la experiencia, son complejas al estar formadas por lo que es cada persona, sus emociones, lo que piensa y cree así como sus valores. 


\section{El paradigma tradicional del liderazgo y sus nuevas concepciones}

Para Zalles (2011), una visión tradicionalista del liderazgo describe al "líder" como: "aquella persona, que, define visiones y metas, organiza actividades, desarrolla e impone normas y dirige las actividades de otros...el grupo le otorga un estatus superior, prominencia, aceptación, obediencia y hasta sumisión a esa persona" (p. 5).

Zalles (2011) opina que los roles para las personas "líderes" no han sufrido mayor variación bajo la visión tradicional, tampoco ha cambiado la posición que se asigna a esas personas. Para Zalles, los cambios claramente discernibles se han dado solo en la relación entre "líder" y "seguidores", en tanto que el ejercicio de esas funciones bajo una atmósfera de la imposición ha evolucionado hacia la inspiración y la motivación de los "seguidores", donde el respeto a sus opiniones y la participación han cobrado importancia y van siendo esenciales.

La investigación realizada partió de la premisa de que el liderazgo tal y como lo define (Heifetz, citado por Zalles, 2011) es una actividad de un ciudadano de cualquier condición, por lo tanto, el liderazgo es una actividad que puede ejercer cualquier persona, sin que necesariamente exista una jerarquización de sus funciones, un puesto o una autoridad impuesta. Desde esta perspectiva, exponer a la persona desde temprana edad a experiencias donde sea parte de un equipo, donde deba asumir diferentes roles y donde sea partícipe de la toma de decisiones pueden ser oportunidades para el desarrollo del liderazgo.

\section{El Liderazgo en la escuela}

Según Maxwell (2007), el liderazgo no se logra de un día para el otro; toma toda una vida, de ahí la importancia de desarrollar las habilidades necesarias desde temprana edad.

En la literatura se encuentra que muchos autores enuncian con variados términos las "características" que debe tener y desarrollar un líder para desempeñarse como tal. Blanchard (2004) les llama conjunto de habilidades, talentos o dones, necesarios para conducir los procesos de cambio. 
Cuando se habla del liderazgo en niños, Ibáñez (2011) menciona que los padres y madres juegan un rol muy importante en liderazgo de sus hijos e hijas, dando el ejemplo, formando a un niño y niña a ver a todos como iguales, que aprenda y conozca sus cualidades, defectos y pueda mejorarlos, que pueda equivocarse y aprender de sus errores.

El grupo Caja de herramientas comunitarias (s.f.) menciona que:

Los líderes en potencia se encuentran en todas partes, aunque su momento no llegue por un buen tiempo. Por esta razón, tiene sentido asumir que todas las personas necesitan desarrollar habilidades de liderazgo, así como la seguridad en sí mismos y la habilidad de usarlas cuando el momento se presente. (¿Quiénes son líderes potenciales?, párr. 3)

Se puede trabajar en desarrollar las habilidades de liderazgo de los niños y las niñas con experiencias que son apropiadas para el desarrollo de su razonamiento lógico, interpersonal y moral. En este sentido, el aula debe ser más que un espacio físico y ser un lugar de interacción, de experiencias cotidianas, de dudas, preguntas y búsqueda de respuestas. Para que esto suceda, Acaso (2009) menciona que el docente debe cambiar su mentalidad y ver la realidad del aula como un espacio socioeducativo. Tal y como dicen Romero et al. (2009) quienes aseguran que, a partir de la interrelación con las personas como se actualizan los modos de ver y hacer, se potencia la capacidad de expresión, la individualidad y las vivencias significativas.

Para que un docente contribuya en la formación de niños y niñas líderes, Blanco (2008) menciona que "lo primero que debe tener un docente (...) es una alta expectativa en los estudiantes, en sus talentos y aptitudes, en creer verdaderamente que puede alcanzar grandes logros" ¿Qué debe tener un docente para formar líderes?, párr. 2)

El aula es un espacio para que emerjan "liderazgos" en paralelo con el del profesorado y que son el fruto natural de cualquier grupo humano, Fox, (citado por Gil et al., 2013) lo llaman liderazgo entre iguales. Por lo que cabe considerar, que el liderazgo desde una perspectiva pedagógica está implícito en la formación humana (López, citado Gil et al., 2013), por tanto, respeta la individualidad, pero más allá de eso mira al ser humano en una realidad social como la que se vive en la escuela. 


\section{Metodología}

Dado que el objetivo de esta investigación, fue identificar los conocimientos que poseen los docentes de primer ciclo de un centro educativo privado de Heredia sobre el juego como estrategia metodológica para el desarrollo de habilidades de liderazgo en niños y niñas de primer ciclo, se abordó la problemática desde las siguientes perspectivas metodológicas.

La investigación realizada fue naturalista que desde la perspectiva de Barrantes (2000) sus propósitos esenciales están destinados a la comprensión de la conducta humana a través del descubrimiento de los significados sociales, ya que se consideraba importante el significado que las y los docentes le daban al juego en el desarrollo de sus clases. Gurdián (2007) al hacer referencia al paradigma naturalista propone que, el mundo sea estudiado en su estado natural, por lo que no hubo ninguna alteración en cuanto al desarrollo normal de las clases de los niños y las niñas.

El enfoque es etnometodológico, desde la perspectiva de Garfinkel citado por Urbano, (2007) sostiene que la experiencia de los actores y sus expresiones verbales poseen su propia dinámica y son importantes, los métodos que utilizan los individuos para dar sentido y al mismo tiempo realizar sus acciones cotidianas toman relevancia en este enfoque. Por su parte Aravena, Kimelman, Micheli, Torrealba y Zúñiga (2006) consideran la etnometodología como el interés por comprender a fondo cómo se construye la realidad social, escudriñando el rol activo que juegan los miembros de un grupo social en la construcción y estructuración de su vida cotidiana. Los estudios etnometodológicos en educación buscan descubrir cómo los propios actores del sistema educativo, educadores, estudiantado, padres, directivos influyen con su modo de hacer las cosas en los fenómenos educativos, en el caso de esta investigación interesaba la utilización de la metodología del juego para el desarrollo de habilidades sociales en las clases cotidianas de niños y niñas de primaria. Como herramientas se utilizan la observación directa en las aulas, observación participante, entrevistas y estudios de registros. 
La investigación se realizó mediante un estudio, el cual "pretende comprender un caso particular, sin interés por comprender otros casos o un problema general... (Creswell, citado por Ceballos-Herrera, 2009 p. 417). En este caso, se detalla a continuación los aspectos trabajados en esta investigación.

En este estudio, participaron ocho docentes de primaria, con grados académicos de bachillerato y licenciatura, todas laboran en una institución privada en la provincia de Heredia, escogidos por conveniencia bajo criterios de accesibilidad y disponibilidad.

Como procedimiento se realizó un análisis de los planeamientos didácticos del primer trimestre realizado por las docentes, donde se enlistaban todas aquellas actividades lúdicas que se destacaban en los planes de clase y la finalidad para la cual se usarían. Así mismo, se realizaron observaciones de aula con el propósito de identificar cuáles estrategias metodológicas utilizaban las docentes durante sus clases.

Por otra parte, se aplicó un cuestionario mixto de doce preguntas, ocho de ellas abiertas y cuatro cerradas, realizado por las investigadoras a las docentes de primer ciclo. Como menciona Galán (2009), el cuestionario es un conjunto de preguntas diseñadas para generar datos necesarios para alcanzar los objetivos propuestos del proyecto de investigación. Dicho cuestionario se aplicó con el propósito de conocer la importancia y utilización que dan las docentes al juego como estrategia metodológica, además, conocer sus inquietudes respecto a la metodología del juego, el conocimiento de habilidades de sociales y de liderazgo en la niñez, así como identificar las áreas de capacitación en que tuvieran necesidad respecto a estos temas.

\section{Principales hallazgos y discusión}

A continuación, la descripción y análisis de datos recopilados de los distintos instrumentos utilizados para la búsqueda de alternativas de solución al problema planteado. La Tabla 1 muestra los datos recopilados de la revisión de planeamientos didácticos de las docentes para primer ciclo. 
Tabla 1. Datos recopilados de los Planes Trimestrales, Materias Básicas, Inglés y Science de 1er Ciclo

\begin{tabular}{|c|c|c|c|c|c|}
\hline $\begin{array}{c}\text { Docente } \\
\text { que utiliza } \\
\text { el juego }\end{array}$ & Nivel & $\begin{array}{l}\text { Utilizan el } \\
\text { juego }\end{array}$ & $\begin{array}{l}\text { Materias que } \\
\text { utilizan juego }\end{array}$ & Tipos de Juego & Objetivo \\
\hline \multirow{3}{*}{4} & I & Sí & $\begin{array}{l}\text { Materias } \\
\text { Básicas }\end{array}$ & $\begin{array}{l}\text { Simón Dice, Gato y Ratón, } \\
\text { Se hunde el Barco. }\end{array}$ & $\begin{array}{l}\text { Distensión, integración } \\
\text { y aprender a seguir } \\
\text { instrucciones. }\end{array}$ \\
\hline & II & Sí & $\begin{array}{l}\text { Materias } \\
\text { Básicas, Inglés } \\
\text { y Science. }\end{array}$ & $\begin{array}{l}\text { Figuras con el cuerpo, } \\
\text { Charadas, Papa caliente, } \\
\text { Memoria, Ahorcado, Simón } \\
\text { dice, Se hunde el Barco. }\end{array}$ & $\begin{array}{l}\text { Rompehielos, Distensión, } \\
\text { Repasar materia y } \\
\text { aprender a seguir } \\
\text { instrucciones. }\end{array}$ \\
\hline & III & Sí & $\begin{array}{l}\text { Materias } \\
\text { Básicas, Inglés } \\
\text { y Science. }\end{array}$ & $\begin{array}{l}\text { Figuras con el cuerpo, } \\
\text { Charadas, Papa caliente, Se } \\
\text { hunde el Barco. }\end{array}$ & $\begin{array}{l}\text { Distensión, Actividad } \\
\text { física, Repasar materia } \\
\text { y aprender a seguir } \\
\text { instrucciones. }\end{array}$ \\
\hline
\end{tabular}


En total, se revisaron los planes del primer trimestre de ocho profesoras de las materias de Español, Matemáticas, Estudios Sociales e Inglés, los cuales se encontró que cuatro de las docentes utilizan el juego en el aula y tres de ellas son de materias básicas y una de inglés. En inglés, el objetivo principal del uso del juego es para repasar materia. Al igual que en Matemáticas, donde se notó un alto grado de utilización del juego según los planeamientos de las docentes, aunque siempre dirigido al repaso de contenidos. Por ejemplo, salen a las zonas verdes, dividen el grupo en subgrupos y los niños y niñas, con los cuerpos, deben ir formando las figuras geométricas que se les piden. De esta actividad, el único insumo importante que se observa es que los niños y niñas dominan las figuras geométricas vistas en clases. No hay evidencia de que se aproveche el espacio para observar las relaciones interpersonales, trabajo en equipo, identificar valores predominantes del grupo o reflexionar después del juego.

Los tres niveles, básicamente, utilizan los mismos tipos de juegos, dirigidos al reforzamiento cognitivo, y a seguir indicaciones, en contraste con las afirmaciones de García y Alarcón (2011), los cuales señalan que el juego es una actividad vital e indispensable para el desarrollo humano, ya que contribuye en lo psicomotriz, afectivo-social e intelectual, y no sólo a última área.

En los planeamientos de primer y tercer grado, se puede notar un espacio para el tema de valores, el cual queda reservado para la hora guía, con las docentes de materias básicas. A continuación el análisis de cuestionario aplicado a docentes de primer ciclo.

Tabla 2. Metodologías que utilizan las docentes con mayor frecuencia en clase

Docente 1 Participativas, constructivistas, depende de los planeamientos en contenidos.

Docente 2 Siempre se refuerzan las actitudes positivas de los niños, para que continúen haciéndolas y los demás empiecen a desarrollarlas también.

Docente 3 Se utilizan modificaciones de conducta a nivel grupal. Hay modificadores de trabajo en clase.

Docente 4 Utilizo el constructivismo y la inteligencia emocional interrelacionadas. 
Docente 5 Comunicativa principalmente pero depende del tema que voy a desarrollar y la clase (estudiantes) se utiliza otra.

Docente 6 Constructivista y conductista, ésta última la uso al dar las instrucciones del trabajo a realizar en el aula y luego ellos con las bases dadas construyen su propio conocimiento.

Docente 7 Se da la oportunidad al estudiante líder para que explique determinada instrucción así los demás le entienden, este mismo anima a los otros a participar. Depende del ánimo que también posee el líder en el momento.

Docente $8 \quad$ No respondió.

Nota: Cuestionario aplicado a docentes de Primer Ciclo, 2011.

Siete de las docentes mencionan acciones que realizan en sus clases para reforzar conductas o corregirlas, además bajo qué paradigma enseñan; sin embargo, no especifican una metodología utilizada, una de las docentes no respondió.

Se puede inferir por sus respuestas, que existe una confusión con los términos que manejan, entre ellos metodología, estrategia y paradigma. Se refieren, básicamente, a los modificadores de conducta que el Comité de Apoyo Institucional provee para casos especiales, sin embargo, no hablan del proceso general que llevan a cabo en sus clases para impartir los temas deseados. Enfocan la educación bajo el paradigma institucional constructivista, aunque evidencian que sus prácticas, en su mayoría, siguen siendo tradicionales y conductistas. Respecto a la importancia que las docentes le dan a la metodología del juego, se encontró lo siguiente (Ver Tabla 3).

Tabla 3. Opinión de las docentes acerca de la importancia de la metodología del juego

Docente 1 Porque es una forma participativa y divertida para asimilar conceptos con mayor facilidad.

Docente 2 Porque los niños esperan y reaccionan mejor si la clase es divertida. 
Docente 3 Es importante ya que el constructivismo nos permite que los chicos aprendan jugando y el juego permite conocer el área emocional, social y física de los niños.

Docente 4 Los estudiantes aprenden de forma significativa y diferente. Mientras juegan integran conceptos, refuerzan el aprendizaje y se enseñan unos a otros.

\begin{tabular}{ll}
\hline Docente 5 & $\begin{array}{l}\text { Porque los niños necesitan desarrollar sus habilidades al } \\
\text { máximo por medio de otras actividades y no necesariamente } \\
\text { estar sentados en una silla durante horas. }\end{array}$ \\
\hline Docente 6 & $\begin{array}{l}\text { Me encanta para mí es indispensable integrar el juego en } \\
\text { el aula pues el niño (a) disfruta mucho más su aprendizaje } \\
\text { y se logra un mejor rendimiento en cuanto la aplicación } \\
\text { del concepto y he comprobado que al pasar del tiempo el } \\
\text { estudiante no olvida lo que aprendió jugando. }\end{array}$ \\
\hline Docente 7 & $\begin{array}{l}\text { Porque al utilizar el juego se pone en práctica distintas } \\
\text { habilidades de los niños. }\end{array}$ \\
\hline Docente 8 & $\begin{array}{l}\text { Porque los niños también deben no solo escribir sino jugar } \\
\text { para así no cansarse tanto en clase. }\end{array}$ \\
\hline Nota: Cuestionario aplicado a docentes de Primer Ciclo, 2011.
\end{tabular}

Para siete de las docentes, la utilización del juego como parte de su práctica cotidiana es de gran importancia, seis de las ellas aseguran que el juego es una importante herramienta de aprendizaje significativo en la asimilación de contenidos además de un espacio para la diversión durante las lecciones. Una, asegura no sólo reforzar el área cognitiva sino que además el área emocional, social y física y dos, afirman que con el uso del juego pueden desarrollar otras habilidades en los niños. Solamente una de ellas hace referencia a su uso con el fin único de distraerlos por un momento para que no se cansen, de lo que se puede inferir es una clase magistral. Al respecto, Torres (2002) menciona que los juegos deben considerarse como una actividad importante en el aula de clase, puesto que aportan una forma diferente de adquirir el aprendizaje, aportan descanso y recreación al estudiante. Estos permiten orientar el interés del participante hacia las áreas que se involucren en la actividad lúdica. En la Tabla 4, se muestran las áreas hacia donde las docentes entrevistadas direccionan las actividades lúdicas que realizan. 
Tabla 4. Áreas en las que las docentes aseguran direccionar los juegos $(\mathrm{N}=8)$

\begin{tabular}{lc}
\hline \multicolumn{1}{c}{ Áreas } & Frecuencia Total \\
Cognitiva & 8 \\
Afectiva-emocional & 8 \\
Social & 8 \\
Física & 3 \\
\hline Nota: Cuestionario para docentes de docentes de Primer Ciclo, 2011. \\
\hline
\end{tabular}

Los datos reflejados en el cuadro anterior muestran la conciencia de las docentes en la importancia del juego para el desarrollo de, al menos, tres de las áreas que componen el desarrollo integral del niño y la niña, aspectos que se debe estimular en todo momento y no solo, en clases de educación física o el recreo. A pesar de sus respuestas, no se encontró evidencia en los planeamientos didácticos de juegos direccionados hacia estas otras áreas. En este sentido, Romero, Escorihuela y Ramos (2009) mencionan que la escuela, tiene delegada una serie de tareas orientadas a contribuir en el desarrollo personal, físico, intelectual, afectivo y relacional. La Tabla 5 muestra las definiciones que las docentes dan sobre Liderazgo.

\section{Tabla 5. Definición de liderazgo por parte de las docentes}
Docente 1 Conductas que lleven a otros o a uno mismo hacia una meta o un mismo fin.

Docente 2 Para mí, es una condición o característica que algunas personas poseen y hacen que otros a su alrededor los sigan en actitud y acciones.

Docente 3 En todo lugar hay liderazgo. Es la capacidad de promover buenas ideas hacia un grupo de personas y lograr que esas personas realicen las propuestas elaboradas por el líder del grupo. Es ser guiador.

Docente 4 Es la capacidad de dirigir a un grupo de personas hacia un objetivo común, puede ser positivo o negativo, impuesto o exigido, adquirido o delegado. Aquel que posee el liderazgo puede ser apoyado o rechazado.

Docente 5 Capacidad para dirigir y poder unir un grupo de personas para llevar a cabo un objetivo. 
Docente 6 Es la acción que realiza una persona en pos de cumplir su propósito logrando para ello mover a un grupo de personas, o bien, a una masa de personas.

Docente 7 Son características especiales que la persona posee y le atribuyen un rol muy importante para dirigir.

Docente 8 Es ser o tener líderes en una institución o cualquier cosa que se realice.

Nota: Cuestionario aplicado a docentes de Primer Ciclo, 2011.

Se puede observar como la concepción principal del término, se encuentra enfocada bajo los conceptos tradicionales de liderazgo que se concibe como una característica con la cual se nace, en ningún caso se menciona que se puede aprender o desarrollar. Las docentes opinan que el liderazgo es la capacidad de dirigir, guiar, unir, a un grupo hacia un objetivo común. Siete de las docentes tienen una idea clara sobre el liderazgo, en cuanto a guiar a un grupo en concordancia con la visión tradicional de liderazgo que menciona Zalles (2011) donde esta función es llevada a cabo por una sola persona que define visiones y metas, organiza actividades, desarrolla e impone normas y dirige las actividades de otros. Respecto a lo anterior, las docentes reconocen como habilidades sociales para el liderazgo lo expresado en la tabla siguiente (ver tabla 6).

\section{Tabla 6. Habilidades sociales para el liderazgo que notan las docentes .en los niños y las niñas}

Docente 1 Iniciativa, organización, guía, apoyo, ayuda, estímulo.

Docente 2 Algunos poseen grandes características de líder, en algunos casos positivas y otros negativas, hacen que sus compañeros, casi por instinto, los sigan.

Docente 3 Liderazgo positivo en cuanto al comportamiento. Liderazgo negativo en cuanto a juegos en el recreo.

Docente 4 Don de mando, al igual que ciertos niños que no se proclaman a sí mismos líderes pero son seguidos y buscados en el momento de toma de decisiones.

Docente 5 A la hora de realizar trabajos en grupo, siempre hay alguno que dirige a los demás en los juegos. 
Docente 6 En el entendimiento de liderazgo para realizar acciones positivas a nuestro ver u opinión, ellos aún no lo manifiestan claramente, deben ser guiados a la acción.

Docente 7 Poder de convencimiento.

Docente 8 Algunos estudiantes son líderes positivos o negativos durante las clases y fuera de ellas.

Nota: Cuestionario aplicado a docentes de primer ciclo, 2011.

Algunas de las docentes mencionan como habilidades sociales para el liderazgo: iniciativa, organización, apoyo, ayuda y estímulo, don de mando, dirección, poder de convencimiento. Existe un contraste en las respuestas a esta pregunta y la anterior, ya que en primera instancia se les preguntó: ¿qué era una habilidad de liderazgo? y no tenían muy clara la idea; sin embargo, en esta pregunta manifiestan, mediante sus respuestas, varias habilidades. Una de ellas asegura que no se manifiestan habilidades de liderazgo en los niños y las niñas posiblemente debido a las edades.

Se podría inferir, que debido a que las docentes no manejan con claridad los conceptos de liderazgo, habilidades sociales o de liderazgo, difícilmente van a ser aspectos en los cuales van a prestar atención día a día en el aula, espacio donde según Rodríguez (2013), un amplio repertorio de acciones y conductas sociales son fruto del aprendizaje y de la experiencia. Al preguntar a las docentes sobre la contribución que hacen desde sus clases al desarrollo de habilidades sociales para de liderazgo, mencionan lo siguiente (ver tabla 7).

\section{Tabla 7.Contribución de las docentes al desarrollo de habilidades sociales en sus clases}

Docente 1 Formando grupos que contengan personas líderes y canalizarlos.

Docente 2 Trato de encauzar en forma positiva ese liderazgo, provocando acciones positivas en ese niño, para que otros las imiten.

Docente 3 Comentar que todos somos líderes y debemos dar el buen ejemplo en nuestros trabajos de clase, comportamientos y juegos. 
Docente 4 En muchas ocasiones, se implementa el trabajo en equipo cambiando de organización en diversos turnos.

Docente 5 Dando roles importantes a todos para descubrir y desarrollar habilidades de liderazgo.

Docente 6 En los trabajos que se realizan en forma grupal y anticipándoles lo que deben proponer y luego desear que cumpla el grupo, se rota la dirección del grupo para permitir las mismas oportunidades a todos e ir formando carácter de líder en ellos.

Docente 7 Cuando se realizan actividades en grupo, se asigna el estudiante que tiene más habilidades para dirigir a los otros y alcanzar la meta, se trata que coopere y que guíe.

Docente 8 Trato de posicionarlos en lugares diferentes.

Nota: Cuestionario aplicado a docentes de primer ciclo, 2011.

Siete de las docentes contribuyen formando equipos de trabajo y cambiando de roles para que todos tengan la oportunidad de liderar.

Una docente asegura que en sus actividades escoge al estudiante que tiene más liderazgo para que guíe a los demás. Sin embargo este tipo de estrategia puede desarrollar un sentimiento de favoritismo hacia el o la estudiante que siempre escoge y de exclusión hacia el resto del grupo e inclusive dejar pasar la oportunidad de encontrar nuevos líderes con habilidades diversas en el grupo que, tal vez, no han tenido protagonismo debido a que no se les ha brindado oportunidad.

Una vez más se puede afirmar que el concepto que manejan, en general, las docentes del estudio, es el tradicional de liderazgo y, debido a esto, no saben cómo enfocar su trabajo hacia otros objetivos tales como el desarrollo de habilidades sociales y dar oportunidad para que emerjan nuevos liderazgos en la clase, tal y como lo menciona el grupo Caja de herramientas comunitarias (s.f.) cuando afirman que las personas necesitan desarrollar habilidades de liderazgo y la habilidad de usarlas cuando el momento se presente trabajando con experiencias que son apropiadas para el desarrollo de razonamiento lógico, interpersonal y moral en la infancia. En la Tabla 8, se muestran las acciones de las docentes para promover la interacción entre el estudiantado. 


\title{
Tabla 8. Acciones de las docentes que promocionan la participación e interacción de los niños y niñas
}

\author{
Docente 1 Motivando, realizando actividades que les gusten, la \\ interacción con diálogo.
}

Docente 2 Siempre en forma ordenada les pido que participen levantando la mano y trato de involucrar a aquellos más tímidos que casi no hablan.

Docente 3 Existe una buena participación siempre, debe promover el respeto y el establecimiento de límites. La interacción es excelente ya que la comunicación debe ser primordial para conocer situaciones emocionales de los niños.

Docente 4 Estimulándolos con la "economía de fichas" y la formación de un grupo VIP al que entran los que participan en la clase.

Docente 5 Incluirlos lo más posible en todas las actividades que se llevan a cabo en el aula y haciéndolos sentir que siempre es importante su aporte y participación.

Docente 6 Constantemente en un interaccionar de preguntas y respuestas al conocer un nuevo tema o contenido y tratando de que ellos relacionen lo nuevo con lo viejo, aprendiendo y así formulen e interioricen el nuevo conocimiento.

Docente 7 Trato de establecer mucha empatía y ponerme en los zapatos de ellos como niños, tratarlos de entender y que las energías sean dinámicas para todos.

Docente $8 \quad$ El trato es importante como los temas se den en clase.

Nota: Cuestionario aplicado a docentes de Primer Ciclo, 2011.

Seis de las docentes describen algunas de las acciones que utilizan para promocionar la participación e interacción de los y las estudiantes durante las lecciones. Si bien es cierto, las respuestas no son muy explícitas, se puede deducir por sus prácticas que ellas fomentan la participación de algunos niños y niñas y solamente la interacción con ella, no entre ellos.

Se observa como una de ellas promueve la participación e interacción de manera excluyente dividiéndolos entre el grupo "selecto" que participa y los que no lo hacen. Dos de las docentes no aportan información significativa ya que no se refieren a ninguna estrategia utilizada, simplemente manifiestan la importancia de que exista participación e interacción en el grupo en concordancia con lo expuesto por 
Romero et al. (2009), cuando mencionan que la interrelación con las personas es importante para actualizar los modos de ver y hacer, potenciando la capacidad de expresión, la individualidad y las vivencias significativas. Las docentes manifestaron algunas áreas en las que desean capacitación, estas se muestran en la siguiente tabla (ver Tabla 9).

Tabla 9. Áreas en las que las docentes desean capacitación.

\begin{tabular}{lc}
\hline \multicolumn{1}{c}{ Áreas propuestas para la capacitación. } & Frecuencia \\
\hline Herramientas lúdicas para desarrollar en el aula. & 4 \\
Metodología aprender jugando. & 3 \\
Cantos, rondas y juegos. & 3 \\
Confección de material didáctico. & 3 \\
Actividades de convivencia & 1 \\
Conocimiento de conceptos relacionados con el iderazgo. & 1 \\
Desarrollo de habilidades de liderazgo en niños. & 4 \\
Transdisciplinaridad. & 2 \\
Capacidad para resolver conflictos de aula. & 3 \\
Herramientas alternativas de evaluación, para la diversidad y & 2 \\
creatividad. & 1 \\
Cómo promover la participación en niños y niñas. & 3 \\
Herramientas lúdicas tecnológicas. & \\
\hline Nota: Cuestionario aplicado a docentes de primer ciclo, 2011. & \\
\hline
\end{tabular}

Todas las áreas mencionadas están relacionadas con el juego y el liderazgo, por lo que es evidente la necesidad de capacitar a las docentes de primer ciclo en alternativas lúdicas que les permitan un mayor estímulo de las diferentes áreas que intervienen en el desarrollo integral, así como al desarrollo de habilidades sociales para el liderazgo en los niños y las niñas.

En este sentido, es bueno rescatar las palabras de Romero et al. (2009), donde aseguran que el docente tiene la responsabilidad de enriquecer su práctica pedagógica con estrategias innovadoras y creativas, lo cual trae no sólo grandes beneficios a los docentes y sus prácticas pedagógicas, sino al estudiantado y su diversidad. 


\section{Conclusiones}

El juego constituye un elemento esencial en el desarrollo integral de la niñez, su aporte es innegable y en la medida en que sea este hallazgo conocido por las personas participantes, puede contribuir a la reflexión sobre la propia práctica y motivar así a la búsqueda de metodologías acordes con la naturaleza infantil.

En esta investigación se encontró que aunque las docentes manifiestan hacer uso del juego en sus lecciones, no hay evidencia de estrategias metodológicas en sus planeamientos, observaciones y entrevistas realizadas que lo demuestren. Las docentes que manifiestan utilizar juego como estrategia metodológica, direccionan el mismo hacia el desarrollo cognitivo únicamente.

Además, se evidencia una visión tradicionalista del liderazgo como simplemente la capacidad de dirigir, guiar o influir, lo cual reduce las posibilidades de que las docentes sean conscientes de la contribución intencional que pueden hacer al desarrollo de habilidades sociales en espacios de interacción entre el estudiantado, aspecto que ha quedado en evidencia en este estudio, ya que no se visualizaron momentos para la reflexión y análisis de actividades por parte de las docentes en conjunto con el estudiantado acerca de aspectos de convivencia cotidiana como la resolución de problemas o la toma de decisiones en equipo.

Permitir espacios para la reflexión en materia de habilidades sociales y liderazgo en la infancia, podrían contribuir a que el docente se visualice como agente de cambio en el aula y fuera de ella. Además, haga partícipe al estudiantado en la toma de decisiones. Con el aprendizaje de metodologías lúdicas, las docentes tendrían más oportunidad de brindar espacios donde los niños y niñas puedan exponerse a situaciones de la vida cotidiana de una manera natural, contribuyendo, de esa forma a buscar las soluciones por sí mismos, desarrollando la autoconfianza y el deseo de afrontar situaciones nuevas.

Por último, la oportunidad que las participantes puedan tener para realizar trabajo interdisciplinario puede representar un aporte importante para introducir, reforzar o consolidar algún contenido concreto del currículo, que enriquezcan aún más el aprendizaje significativo y la trasferencia de conocimientos en los niños y niñas, tomando en cuenta así disciplinas relacionadas con el arte, el movimiento humano, la espiritual entre otras. 


\section{Referencias bibliográficas}

Acaso, M. (2009). La educación artística no son manualidades. Nuevas prácticas en la enseñanza de las artes y cultura visual. Madrid: Los libros de la Catarata.

Aravena, M., Kimelman, E., Micheli, B., Torrealba, R. y Zúñiga, J. (Comps.). (2006). Investigación Educativa I. Compilación recuperado de http://jrvargas.files.wordpress.com/2009/11/investigacion-educativa.pdf

Azofeifa. A, y Cordero. M. (2011). El juego como estrategia metodológica para el desarrollo de habilidades de liderazgo en niños y niñas de primer ciclo de un centro educativo privado en Heredia (Tesis de maestría no publicada). Universidad Nacional. Heredia, Costa Rica.

Barrantes, R. (2000). Investigación: Un camino al conocimiento. Un enfoque cuantitativo y cualitativo. San José, Costa Rica: EUNED.

Blanchard, (2004). Gerencia del comportamiento organizacional. VIII Edición. Prentice Hall México.

Blanco, A. L. (1 de noviembre de 2008). Educación de niños preescolares y liderazgo [Mensaje en un blog]. Recuperado de http:// preescolarhoy.blogspot.com/2008/11/educacion-de-nios-preescolares-y.html

Caja de Herramietas Comunitarias (s.f.). Fomentar el desarrollo del liderazgo a lo largo de la vida. (¿quiénes son líderes potenciales, 2013, párr. 3), Recuperado de http://ctb.ku.edu/es/search/node/ Fomentar $\% 20$ el $\% 20$ desarrollo $\% 20$ del $\% 20$ liderazgo $\% 20 \mathrm{a} \% 20$ lo\%20largo $\% 20 \mathrm{de} \% 201 \mathrm{a} \% 20$ vida

Ceballos-Herrera, F. A. (enero-junio, 2009). El informe de investigación con estudio de casos. Magis, Revista Internacional de Investigación en Educación, 1(2), 413-423. Recuperado de http:// www.redalyc.org/articulo.oa?id=281021548015

De la Herrán, A. (2008). Metodología didáctica en educación secundaria: Una perspectiva desde la didáctica general. En A. De La Herrán y J. Paredes (eds.), Didáctica General. La práctica de la enseñanza en la educación infantil, primaria y secundaria (pp. 134-148). Madrid: McGraw-Hill. 
Galán, M. (2009). El cuestionario en la investigación. Recuperado de http://manuelgalan.blogspot.com/2009/04/el-cuestionario-en-la-investigacion.html

Garaigordobil, M. (2009). El juego en el niño equivale al trabajo en el adulto. América Latina Unida. Recuperado de http://americalatinaunida.wordpress.com/tag/juegos-competitivos/

García, H. (2010). Competencias docentes para el siglo XXI (Didáctica lúdica). Recuperado de http://educativocarlos.blogspot. com/2010/01/competencias-docentes-para-el-siglo-xxi.html

García, E.y Alarcón, M. (2011). Influencia del juego infantil en el desarrollo y aprendizaje del niño y la niña. EF Deportes.com, Revista Digital. Buenos Aires, Añol5 (153). 1. Recuperado de http://www.efdeportes.com/efd153/influencia-del-juego-infantil-en-el-desarrollo.htm

Urbano, H. (2007). El enfoque etnometodológico en la investigación cientifica. Liberabit: Lima, Perú. 13: 89-91.

Gil, F., Buxarrais, M., Muñoz, .J y Reyero, D. (2013). El liderazgo educativo en el contexto del aula. XXXII seminario interuniversitario de teoría de la educación. Liderazgo y Educación. Santander, España: Universidad de Cantabria.

Gurdián, A. (2007) El paradigma cualitativo en la investigación socioeducativa. Costa Rica: CECC_AECI.

Maxwell, J. (2007). Las 21 Cualidades indispensables de un Líder. Estados Unidos. Grupo Nelson.

Restrepo y Londoño (2008). La educación física en el fortalecimiento de las habilidades sociales de los estudiantes del grado primero de la Institución Educativa Eduardo Santos, Universidad de Antioquia. Medellín, Colombia: Instituto Universitario de Educación Física. Recuperado de http://viref.udea.edu.co/contenido/ pdf/197-laeducacionfisica.pdf

Rodríguez, C. (2013). Habilidades sociales: Educar para las relaciones sociales. Educapeques. [Mensaje en un blog]. Recuperado de http://www.educapeques.com/escuela-de-padres/habilidades-sociales-educar-para-las-relaciones-sociales.html

Romero, L., Escorihuela, Z. y Ramos, A. (2009). La actividad lúdica como estrategia pedagógica en educación inicial. Revista Digital - Buenos Aires - Año 14 (131).Recuperado de http://www.efdeportes.com/ 
Sales, C. (2005). Análisis de las estrategias de enseñanza con tecnologías de la información ¿Un nuevo contexto metodológico en secundaria? (Tesis Doctoral, Universidad de Valencia). Recuperado de http://hdl.handle.net/10803/9654

Torres, C. (2002). El juego como estrategia de aprendizaje en el aula. Recuperado de http://www.saber.ula.ve/bitstream/123456789/17543/2/carmen_torres.pdf

Zalles, J. H. (2011). Liderazgo: Un concepto en evolución Ecuador. Cuadernos Volumen 3. Democráticos. Editor, Konrad Adenauer Stiftung. Ecuador. 